\title{
Effect of Postbiotic Based on Lactic Acid Bacteria on Semen Quality and Health of Male Rabbits
}

\author{
Jesús V. Díaz Cano ${ }^{1}\left(\mathbb{D}\right.$, María-José Argente $^{2}\left(\mathbb{D}\right.$ and María-Luz García ${ }^{2, *(D)}$ \\ 1 Pentabiol S.L., Polígono Noain-Esquiroz s/n, 31110 Pamplona, Spain; jesus@pentabiol.es \\ 2 Centro de Investigación e Innovación Agroalimentaria y Agroambiental (CIAGRO-UMH), \\ Miguel Hernández University, 03312 Orihuela, Spain; mj.argente@umh.es \\ * Correspondence: mariluz.garcia@umh.es
}

Citation: Díaz Cano, J.V.; Argente, M.-J.; García, M.-L. Effect of Postbiotic Based on Lactic Acid Bacteria on Semen Quality and Health of Male Rabbits. Animals 2021, 11, 1007. https://doi.org/10.3390/ani11041007

Academic Editor: Francesco Gai

Received: 23 February 2021

Accepted: 31 March 2021

Published: 3 April 2021

Publisher's Note: MDPI stays neutral with regard to jurisdictional claims in published maps and institutional affiliations.

Copyright: (c) 2021 by the authors. Licensee MDPI, Basel, Switzerland. This article is an open access article distributed under the terms and conditions of the Creative Commons Attribution (CC BY) license (https:/ / creativecommons.org/licenses/by/ $4.0 /)$.
Simple Summary: Postbiotics, especially those derived from metabolites of Lactobacillus, have been proposed as an alternative to the use of antibiotics for prevention and treatment of some diseases. This study was performed in rabbits due to their economic importance as a livestock species in Mediterranean countries, as well as being an experimental model in biomedicine. In this work, the use of a diet enriched with a postbiotic based on lactic acid bacteria is proposed to improve the seminal characteristics of rabbits and their health.

\begin{abstract}
The aim of this study was to evaluate the effect of lactic acid bacteria-based postbiotic supplementation on semen characteristics and hematological and biochemical profiles in rabbits. A total of 28 males were randomly allocated into two groups. Males received a Control diet and Enriched diet supplemented with postbiotic for 15 weeks (4 weeks of adaptation period and 11 weeks of experimental period). Body weight, feed intake and semen characteristics were recorded weekly. Hematological profile was recorded at the beginning and end of the experiment and biochemical profile at 0, 5, 10 and 15 weeks. Bayesian methodology was used for the statistical analysis. Feed intake was higher in Control diet (125.2 g) than in the Enriched diet (118.6 g, $p=1.00)$. The percentages of abnormal spermatozoa were higher in Control diet than in Enriched diet (30\% and 22\%; $p=0.93)$ and the acrosome integrity percentage was lower $(97 \%$ and $96 \% ; p=0.87)$. The hematological profile was within the range for healthy rabbits. The plasmatic level of alanine aminotransferase was higher in Control diet than Enriched diet at 5 and 10 weeks ( $p=0.93$ and $p=0.94$, respectively) and alkaline phosphatase was similar in Control diet throughout the experiment, but decreased in Enriched diet $(p=0.97)$. No difference was found in kidney parameters (uric nitrogen and creatinine). Enriched diet showed higher total protein and globulin than Control diet $(p=0.99)$. Phosphorus was lower $(p=0.92)$ in Control diet than in Enriched diet. In conclusion, the addition of the postbiotic based on lactic acid bacteria seems to improve the quality of the semen and the liver profile in rabbits.
\end{abstract}

Keywords: fermented food; hepatic profile; lactic acid bacteria; postbiotic; rabbit; semen profile

\section{Introduction}

Probiotics are live microorganisms which, when administered in adequate amounts, confer health benefits on the host [1]. Probiotic microorganisms are primarily lactic acidproducing bacteria of the genus Lactobacillus [2]. These probiotics can regulate the balance of gut microbes, promote the growth and productivity of animals and improve host resistance to diseases [3]. To this end, they have been extensively used in dairy cattle [4], beef cattle [5], pigs [6], hens [7] and rabbits [8]. Postbiotics are defined as soluble products or metabolites secreted by probiotics that have physiological benefits to the host [9]. Postbiotics consist of a wide range of effector molecules [10] and they are capable of reducing the gut $\mathrm{pH}$ and, in turn, inhibiting the proliferation of opportunistic pathogens in the feed and gut microbiota $[10,11]$. Postbiotics, especially those derived from metabolites of 
Lactobacillus, have been proposed as an alternative to the use of antibiotics, not only in humans, but also in monogastrics [12]. Currently, the application of postbiotics in human food, animal feed and pharmaceutical industries is increasing and postbiotic products derived from Lactobacillus species are commercially available for prevention or treatment of some diseases [10].

Rabbit is a livestock species reared either for the production of meat, hair or skin or as an experimental reference for other species, such as pigs or humans [13]. In rabbit meat production, artificial insemination is being widely used in intensive production farms [14] The success of artificial insemination programs in rabbits depends to a great extent on both male health and reproductive performance [15]. Thus, the productivity, welfare and health of males should be improved by handling or feeding. Unlike other monogastric animals, data on the use of postbiotics in rabbits are quite scarce [12]. The aim of this study is to study the effect of supplementation with a postbiotic based on lactic acid bacteria on semen characteristics and hematological and biochemical profiles in male rabbits.

\section{Materials and Methods}

\subsection{Ethics Statement}

All experimental procedures were approved by the Miguel Hernández University of Elche Research Ethics Committee, according to Council Directives 98/58/EC and 2010/63/EU (reference number 2019/VSC/PEA/0163).

\subsection{Product Description}

The fermented food product tested was the result of a specific process of fermentation of a substrate and a combination of specific lactic acid bacteria and yeast. The substrate was a plant-based food product primarily composed of soya, alfalfa and wheat, along with other minor components. The fermented food product contained the phyla Firmicutes (38.7\%), Proteobacteria (26.7\%), Bacteroidetes (18.3\%), Actinobacteria (14.5\%) and Saccharibacteria $(1.8 \%)$. At genus level, Lactobacillus was the predominant, accounting for more than $6 \%$ of identified species [16].

\subsection{Animals}

A total of 28 rabbit males aged between 9 and 12 months were used [17]. The animals were kept on an experimental farm at the Universidad Miguel Hernández de Elche (Spain). All animals were reared in individual cages $(37.5 \times 33 \times 90 \mathrm{~cm})$ during the entire experiment. The photoperiod was $16 \mathrm{~h}$ light: $8 \mathrm{~h}$ dark.

\subsection{Diets}

Two diets were used. The control diet presented the following composition: $17 \%$ crude protein, $15 \%$ crude fiber, $9 \%$ crude ash, $3.6 \%$ crude fat, $1.2 \%$ calcium, $0.6 \%$ phosphorus and $0.3 \%$ sodium. The enriched diet presented the same composition supplemented with $2.0 \mathrm{~kg}$ of a fermented food product in a ton of feed.

\subsection{Experimental Design}

Animals were randomly divided into two groups of 14 males each; one group received the Control diet and the other the Enriched diet. Animals had a 4-week adaptation period to the feed. The experimental procedure lasted 11 weeks. Animal body weight and feed intake were recorded weekly.

\subsection{Semen Collection and Evaluation}

Two ejaculates per male were collected each week on a single day using an artificial vagina, with a minimum of $30 \mathrm{~min}$ between ejaculate collections. After the adaptation period, semen evaluations were performed for 11 weeks. If gel was present, it was removed. Only ejaculates exhibiting a white color were classified as normal and were evaluated. Ejaculates were diluted (dilution 1:5) with TRIS-citrate-glucose extender. Percentages of motile 
sperm were evaluated subjectively (from 0 to 5 ) under a microscope at a magnification of $400 \times$ with a thermostatic plate set at $37^{\circ} \mathrm{C}$.

An aliquot from each ejaculate $(0.1 \mathrm{~mL})$ was fixed with $0.9 \mathrm{~mL}$ of $2 \%$ glutaraldehyde solution in DPBS. The sperm concentration was determined using a Thoma-Zeiss cell counting chamber (Marienfield, Germany). A total of 100 spermatozoa were evaluated at a magnification of $400 \times$ with a differential interface contrast microscope (Normarski contrast). Spermatozoa were classified as normal or abnormal. The percentage of abnormal spermatozoa was calculated. Abnormalities were referred to tail, head and middle piece. Their percentages were calculated. Presence of cytoplasmic droplets and status of the acrosome (intact or damaged) in the normal spermatozoa were evaluated and their percentages were calculated.

\subsection{Blood Collection and Biochemical and Haematological Parameters}

Following the blood sampling procedure described in [18], blood samples were collected into a tube with tripotassium ethylenediaminetetraacetic acid (K3-EDTA) at weeks 0 and 15. Hematological parameters such as white blood leukocyte count (WBC, 103/ $\mu \mathrm{L}$ ) and percentage of lymphocytes, neutrophils, monocytes, basophils and eosinophils were determined with the Abacus Junior Vet hematology analyzer (Diatron, Austria).

Blood samples were collected into a lithium heparin tube at weeks 0, 5, 10 and 15 . After centrifugation at $4000 \mathrm{rpm}$ for $15 \mathrm{~min}$, the concentrations of total bilirubin (TBIL, $\mu \mathrm{mol} / \mathrm{L}$ ), alkaline phosphatase (ALP, U/L), albumin (ALB, g/L), alanine aminotransferase (ALT, U/L), total protein (TP, g/L), globulin (GLOB, g/L), glucose (GLU, mmol/L), creatinine (CRE, $\mu \mathrm{mol} / \mathrm{L})$, uric nitrogen $(\mathrm{BUN}, \mathrm{mmol} / \mathrm{L})$, amylase (AMY, $\mathrm{U} / \mathrm{L})$, calcium $\left(\mathrm{Ca}^{2+}, \mathrm{mmol} / \mathrm{L}\right)$, potassium $(\mathrm{K}+, \mathrm{mmol} / \mathrm{L})$, sodium $(\mathrm{Na}+, \mathrm{mmol} / \mathrm{L})$ and phosphorus (FOS, $\mathrm{mmol} / \mathrm{L}$ ) were assessed. These biochemical parameters were determined with VETSCAN Comprehensive Diagnostic Profile Rotors (Diatron, Austria).

\subsection{Statistical Analyses}

2.8.1. Survival, Body Weight and Feed Intake

A Kaplan-Meier plot was used for the survival analyses (GraphPad Prism 9.0.0)

Body weight and feed intake were analyzed using the following model:

$$
Y i j k l=\mu+W i+D j+W i \times D j+m i j k+e i j k l,
$$

where Wi is the week effect $(i=15), D j$ is the diet effect $(j=2$; Control diet and Enriched diet); $\mathrm{Wi} \times \mathrm{Dj}$ is the interaction between week and diet, mijk is the random effect of the male and eijkl is the residual term. The body weight was also included as covariate for feed intake

\subsubsection{Seminal Parameters}

The percentage of normal ejaculates was analyzed using Chi-square test. Seminal parameters were analyzed using the following model:

$$
\text { Yijklm }=\mu+\mathrm{Oi}+\mathrm{Wj}+\mathrm{Dk}+\text { mijkl }+ \text { eijklm, }
$$

where $\mathrm{Oi}$ is the collection order effect ( $\mathrm{i}=2$; first and second), $\mathrm{Wj}$ is the week effect $(\mathrm{j}=11)$, $\mathrm{Dk}$ is the diet effect ( $\mathrm{k}=2$; Control diet and Enriched diet), mijkl is the random effect of the male and eijklm is the residual term.

\subsubsection{Hematological and Biochemical Traits}

Data were analyzed using the following model:

$$
\text { Yijkl }=\mu+W i+D j+W i \times D j+m i j k+e i j k l,
$$


where $\mathrm{Wi}$ is the week effect $(i=2$, week 0 and 15 for haematological traits; $i=4$, week 0 , 5, 10 and 15 for biochemical traits), $\mathrm{Dj}$ is the diet effect $(\mathrm{j}=2$; Control diet and Enriched diet); $\mathrm{Wi} \times \mathrm{Dj}$ is the interaction effect, mijk is the random effect of the male and eijkl is the residual term.

Residuals and male effects were assumed to be independently normally distributed with the same variance. A Bayesian analysis was used, with bounded flat priors for all unknown parameters. Marginal posterior distributions were estimated for all unknowns using Gibbs sampling. Marginal posterior distributions of the differences between lines were computed with the Rabbit software program developed by the Institute for Animal Science and Technology (Valencia, Spain), using Monte Carlo Markov chains of 60,000 iterations, with a burn-in period of 10,000, and only 1 out of every 10 samples was saved for inferences. Convergence was tested using the $\mathrm{Z}$ criterion of Geweke and Monte Carlo sampling errors were computed using time-series procedures.

Results are presented with Bayesian methodology. We provide the difference between diets $\left(D_{D-E}\right)$ and the precision of our estimation, finding the shortest interval with $95 \%$ probability of containing the true value, which can be asymmetric around the estimation. This is called the highest posterior density interval at $95 \%$ probability. We also calculate the actual probability of the difference between the Control diet and Enriched diet $\left|D_{D-E}\right|$ being higher than zero. We consider that there is enough evidence for the Control and Enriched diets being different when the probability of this difference in absolute value $\left|D_{D-E}\right|$ is more than $90 \%$.

\section{Results}

\subsection{Survival, Body Weight and Feed Intake}

Males fed with Enriched diet displayed a similar survival rate to those on Control diet (Figure 1a). Survival rate was 78.6\% for Enriched diet and $73.3 \%$ for Control diet (Chi-square $=0.07 ; \mathrm{P}$ value $=79 \%$; data not shown in tables) .

In general, body weight was $3514 \mathrm{~g}$ in Control diet and $3433 \mathrm{~g}$ in Enriched diet $(p=$ 0.85 , Table 1). Feed intake was $5 \%$ higher with the Control diet (125.2 g) than with the Enriched diet (118.6 g; $p=1.00)$. This difference was not due to a higher body weight of Control diet, as when the body weight was included as a covariate, the difference between diets was maintained. The evolution of the body weight and feed intake each week is shown in Figure 1b.
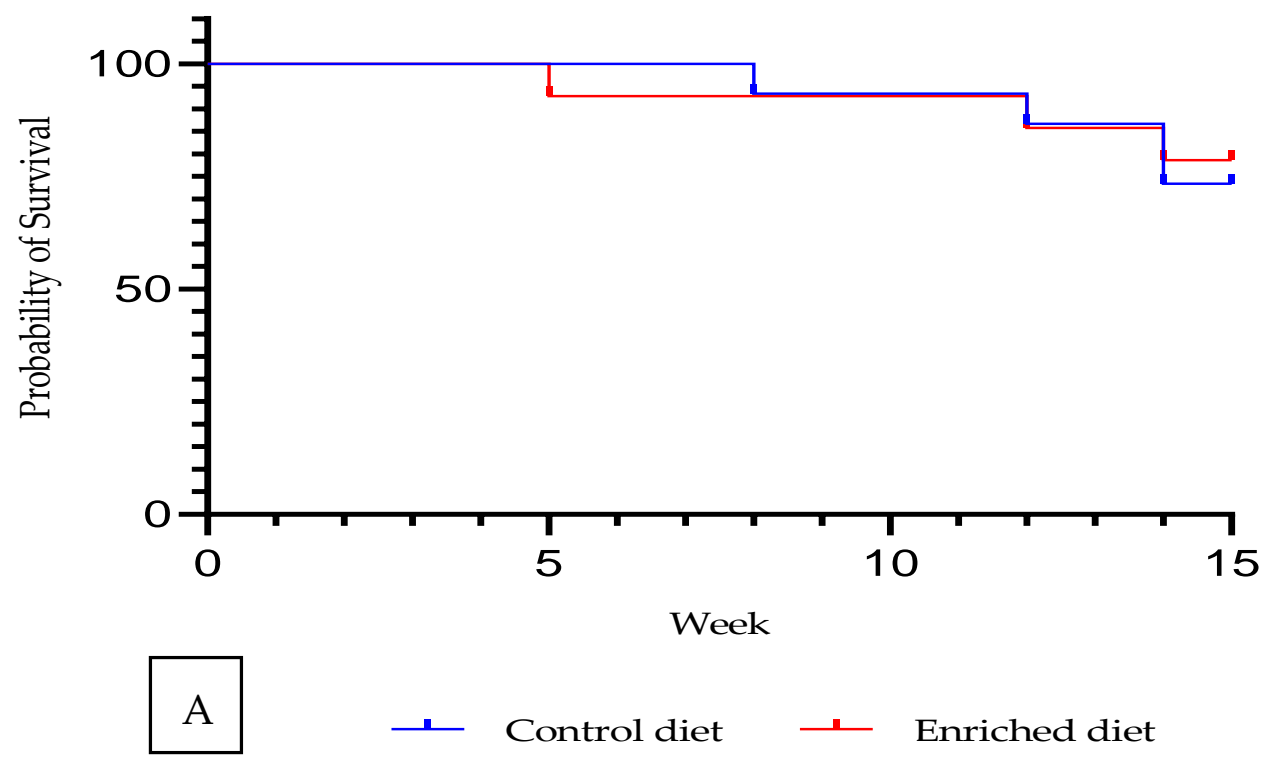

Figure 1. Cont. 


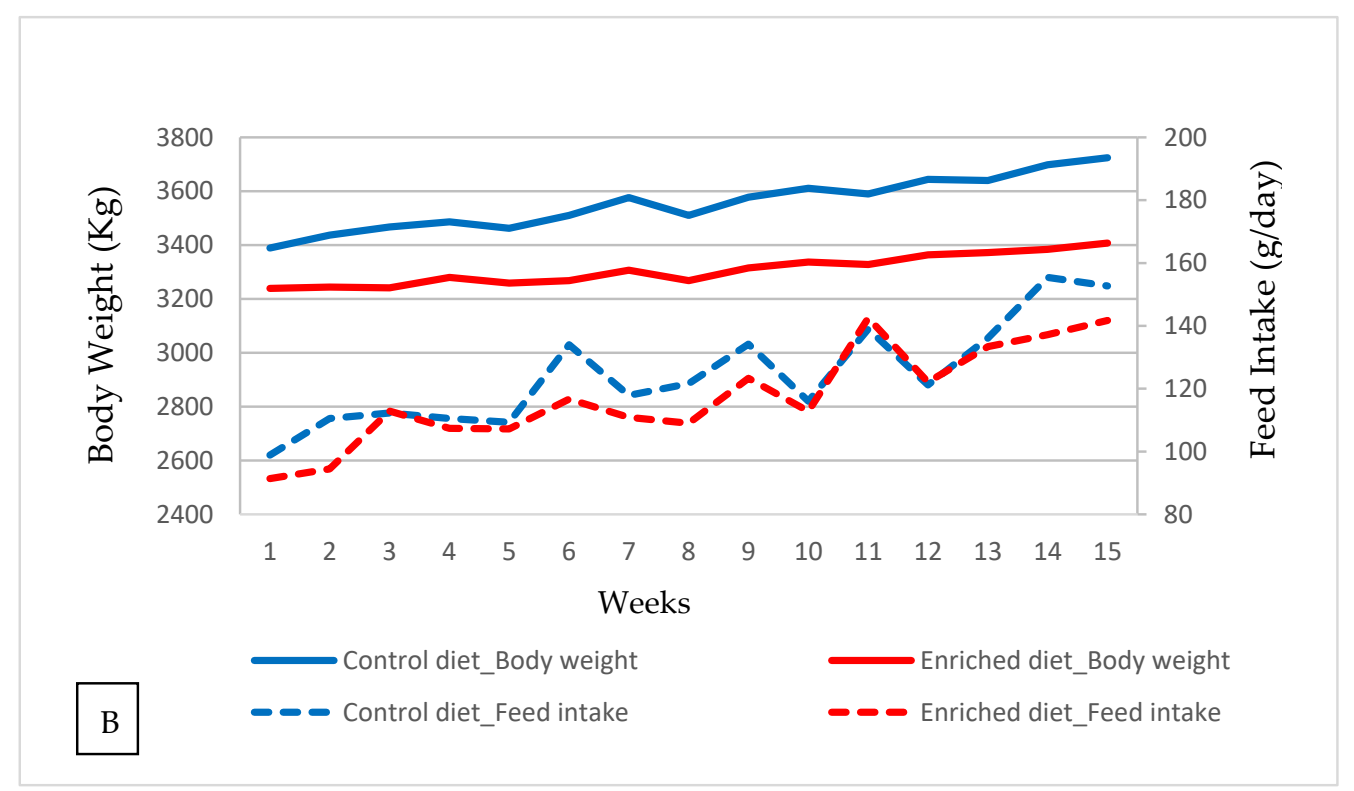

Figure 1. Control and Enriched diet: (A) Kaplan-Meier plot. (B) Evolution of body weight and feed intake.

Table 1. Effect of diet on body weight and feed intake in male rabbits.

\begin{tabular}{cccccc}
\hline & D & E & D $_{\text {D-E }}$ & HPD $_{\mathbf{9 5} \%}$ & P \\
\hline Body weight (g) & 3514 & 3443 & 71 & $-66,202$ & 0.85 \\
Feed intake (g/day) & 125.2 & 118.6 & 6.6 & $2.0,10.7$ & 1.00 \\
Feed intake (g/day) $^{*}$ & 125.3 & 118.3 & 7.0 & $2.7,11.4$ & 1.00 \\
\hline
\end{tabular}

D: Median of the Control diet; E: Median of the Enriched diet; $\mathrm{D}_{\mathrm{D}-\mathrm{E}}$ : Difference between the Control and Enriched diet; $\mathrm{HPD}_{95 \%}$ : Highest posterior density region at $95 \%$; P: Probability of the difference being $>0 .{ }^{*}$ Body weight as covariate.

\subsection{Sperm Quality}

Both diets showed similar percentages of eliminated ejaculates due to low macroscopic quality $(12 \%$ in the Control diet and $14 \%$ in the Enriched diet; Chi-square $=0.58 ; p=45 \%$; data not shown in tables).

Volume, motility and production were similar in both diets (Table 2). Enriched diet showed a lower percentage of abnormal spermatozoa than Control diet $(22 \%$ and $30 \%$, respectively; $p=0.93)$. This difference was due to the lower percentage of tail abnormalities $(16 \%$ and $24 \%$, respectively; $p=0.90)$. Similar percentages of head and middle piece abnormalities were found in both diets ( $4 \%$ and $2 \%$, respectively).

Table 2. Effect of diet on sperm quality in male rabbits.

\begin{tabular}{cccccc}
\hline & D & E & D $_{\text {D-E }}$ & HPD $_{95 \%}$ & P \\
\hline Volume (mL) & 1.09 & 1.13 & 0.04 & $-0.27,0.18$ & 0.64 \\
Motility & 3.72 & 3.75 & -0.03 & $-0.07,0.62$ & 0.53 \\
Production (106 spz) & 266.2 & 269.1 & -3.3 & $-75,7,63.1$ & 0.54 \\
Abnormal spz (\%) & & & & & \\
Total (\%) & 30 & 22 & 8 & $-2,18$ & 0.93 \\
Head (\%) & 4 & 4 & 0 & $-3,2$ & 0.64 \\
Tail (\%) & 24 & 16 & 8 & $-5,18$ & 0.90 \\
Middle piece (\%) & 2 & 2 & 0 & $-1,1$ & 0.62 \\
Cytoplasmic droplet (\%) & 12 & 10 & 2 & $-5,8$ & 0.69 \\
Acrosome integrity (\%) & 96 & 97 & -1 & $-3,1$ & 0.87 \\
\hline
\end{tabular}

D: Median of the Control diet; E: Median of the Enriched diet; $\mathrm{D}_{\mathrm{D}-\mathrm{E}}$ : Difference between Control and Enriched diet; $\mathrm{HPD}_{95 \%}$ : Highest posterior density region at $95 \%$; P: Probability of the difference being $>0$ when $\mathrm{D}_{\mathrm{D}-\mathrm{E}}>0$ or being $<0$ when $\mathrm{D}_{\mathrm{D}-\mathrm{E}}<0$. 
A similar cytoplasmic droplet was shown for both diets $(p=0.69)$. Acrosome integrity was higher in Enriched than Control diet (97\% and $96 \%$ respectively; $p=0.87$ ).

\subsection{Hematological and Biochemical Parameters}

Figure 2 shows the hematological parameters for diets at the beginning and end of the experiment. Lymphocytes increased by $15 \%$ and $20 \%$ in the Control diet $(p=0.90)$ and in the Enriched diet $(p=0.93)$. Monocytes increased for the Control diet $(p=0.97)$, but they did not vary in the Enriched diet. Neutrophils decreased in the Control diet $(p=0.90)$ and in the Enriched diet $(p=0.99)$. Eosinophils and basophils increased from week 0 to 15 in both Diets ( $p=1.00$ and $p=0.91$, respectively). WBC did not vary between diets or throughout the experiment, ranging between 8.4 and $9.6 \times 10^{3} / \mu \mathrm{L}$ (data not shown in tables).

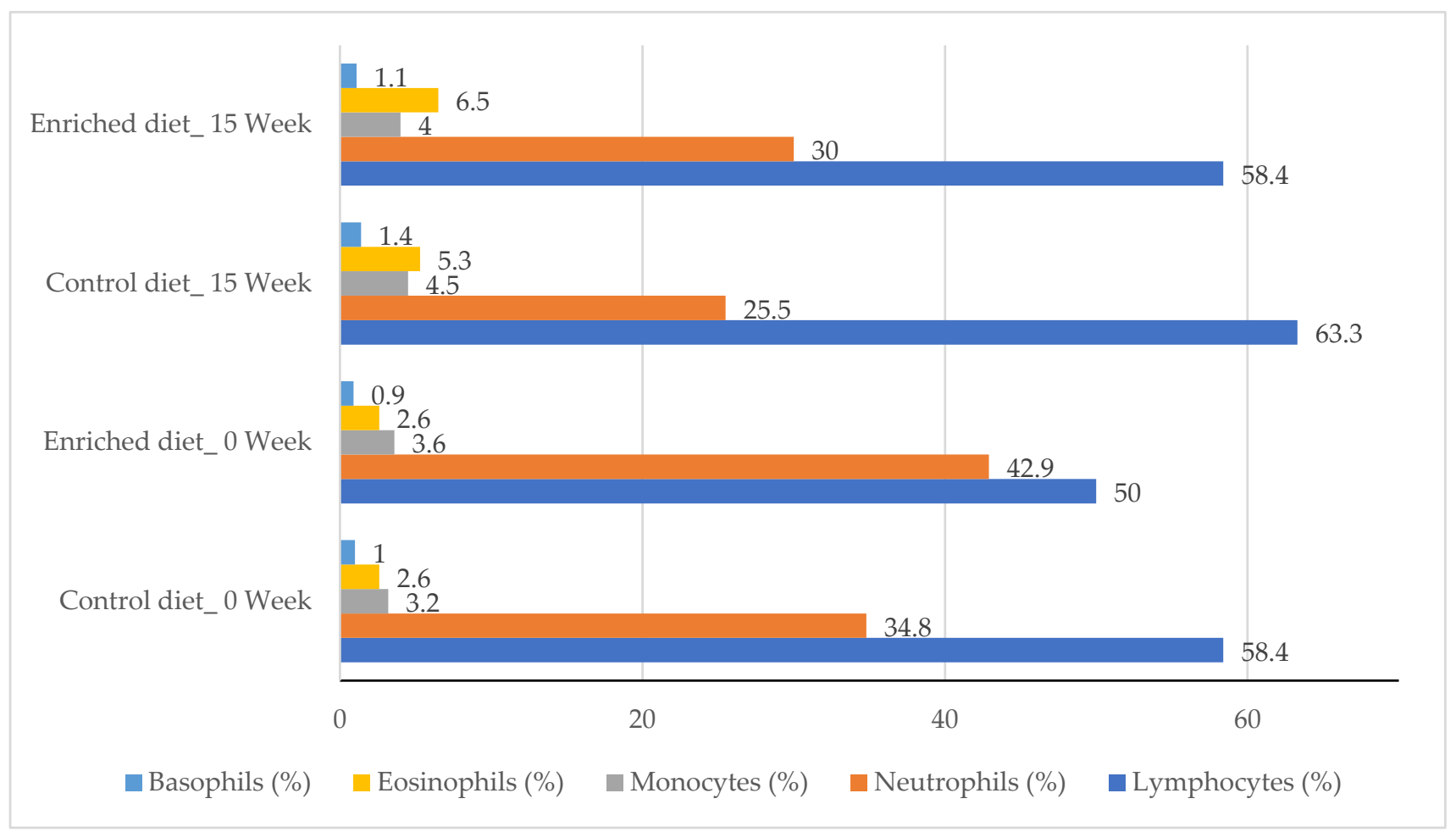

Figure 2. Percentage of lymphocytes, neutrophils, monocytes, eosinophils and basophils for Control and Enriched diets at 0 and 15 weeks.

Alanine aminotransferase is shown for Control and Enriched diets at 0, 5, 10 and 15 weeks in Figure 3a. Alanine aminotransferase was higher in the Control diet than in the Enriched diet at 5 weeks $(p=0.93)$ and at 10 weeks $(p=0.94)$. Both diets decreased the levels of alanine aminotransferase, but this decrease was lower in Control diet $(5.6 \mathrm{U} / \mathrm{L}$; from 50.2 to $44.6 \mathrm{U} / \mathrm{L})$ than in Enriched $\operatorname{diet}(6.0 \mathrm{U} / \mathrm{L}$; from 43.5 to $37.5 \mathrm{U} / \mathrm{L} ; p=0.95$; results not shown in Figure). Alkaline phosphatase was similar for both diets and throughout the entire control period (Figure 3b). Nevertheless, while the difference between 0 and 15 weeks was similar in Control diet ( 39.6 and $35.5 \mathrm{U} / \mathrm{L}$, respectively; $p=0.62$ ), the alkaline phosphatase exhibited relevant reduction in Enriched diet (42.7 and $35.5 \mathrm{U} / \mathrm{L}$, respectively; $p=0.97)$. Amylase tends to be higher in Control diet than in Enriched diet, showing differences at week 10 ( $p=0.95$; Figure 3c). Glucose was similar for both diets and ranged from 5.6 to $6.5 \mathrm{mmol} / \mathrm{L}$ (Figure 3d). 


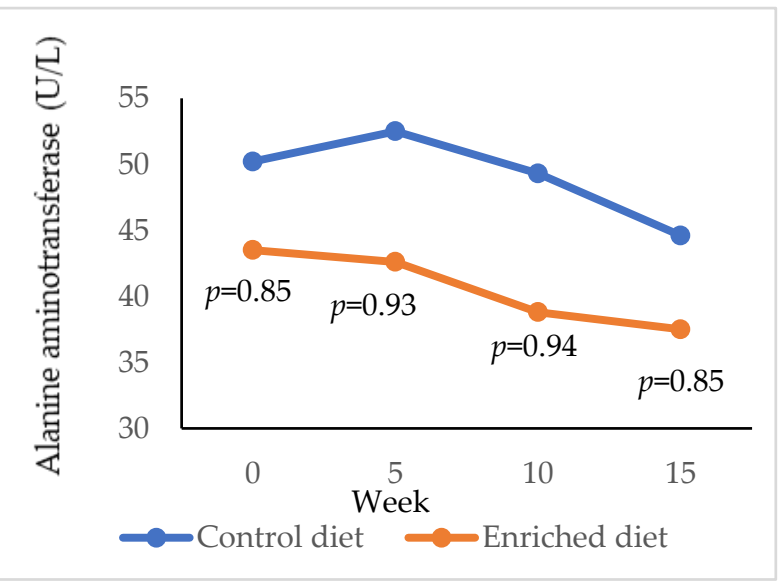

(a)

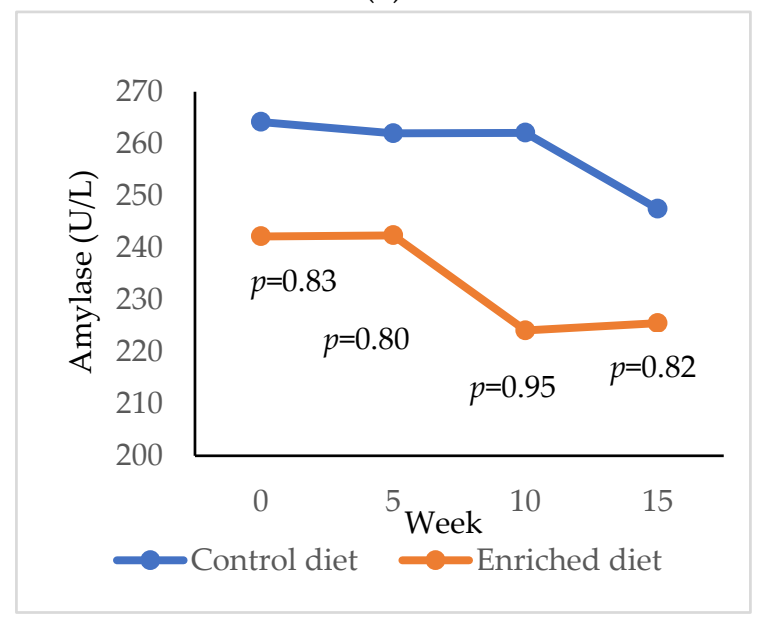

(c)

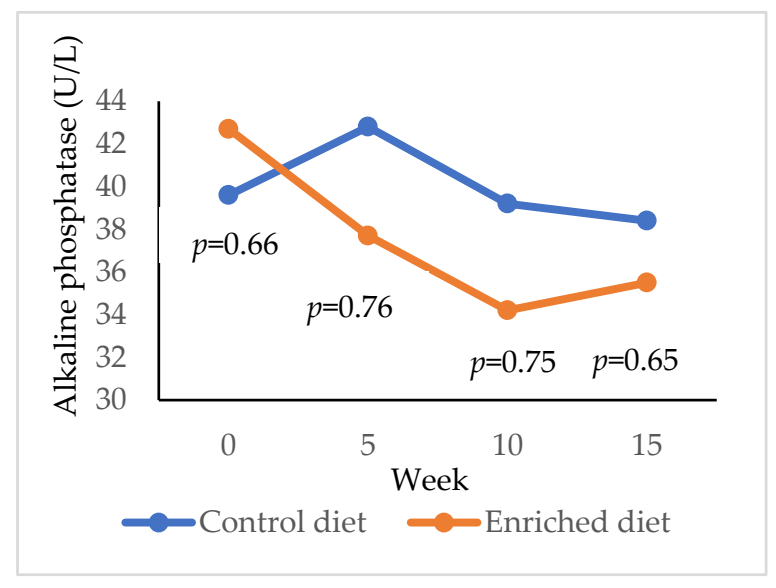

(b)

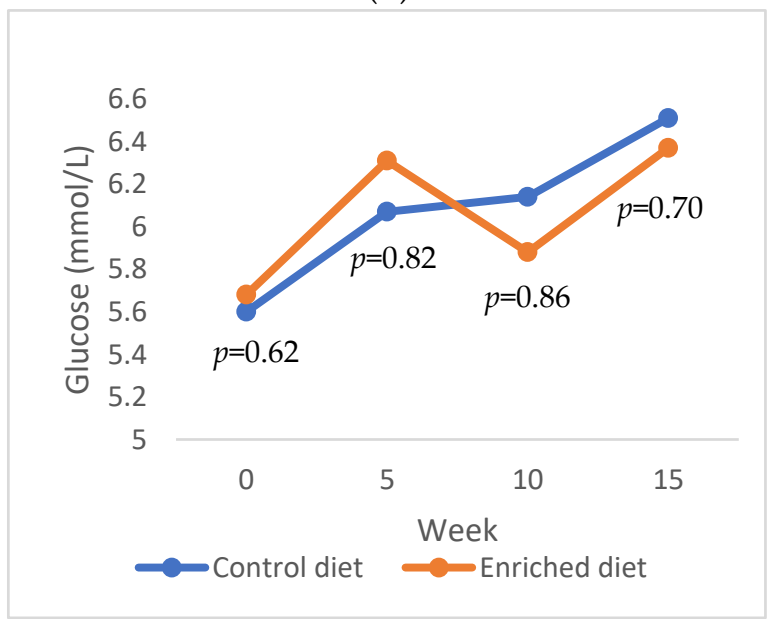

(d)

Figure 3. Evolution of (a) alanine aminotransferase; (b) alkaline phosphatase; (c) amylase; (d) glucose in males fed with Control and Enriched diet. $p$ is the probability of the difference being $>0$ when the difference between the diets was $>0$ or being $<0$ when this difference was $<0$.

Enriched diet showed a higher total protein than Control diet after the adaptation period $(+2.68 \mathrm{~g} / \mathrm{L} ; p=0.99$; Figure $4 \mathrm{a})$ and was maintained until week $10(+3.09 \mathrm{~g} / \mathrm{L}$; $p=0.99)$. However, after feeding Enriched diet for 15 weeks, the total protein was similar to Control diet. Control diet showed a lower globulin concentration than the Enriched diet at both $5(p=0.98$; Figure $4 \mathrm{~b})$ and 10 weeks $(p=0.99)$. Albumin was higher at the start of the experiment in the Control diet $(22.9 \mathrm{~g} / \mathrm{L}$; Figure $4 \mathrm{c})$ than in the Enriched diet $(21.9 \mathrm{~g} / \mathrm{L}$; $p=0.94)$. Both diets presented similar albumin from 5 to 15 weeks.

Control diet showed higher creatinine values than the Enriched diet $(p=0.92)$ at week 0 , but the values were similar at weeks 5, 10 and 15 (Figure 5a). Both diets decreased creatinine during the experiment $(-20.8 \mu \mathrm{mol} / \mathrm{L}$ in Control diet, $p=1.00 ;-30.5 \mu \mathrm{mol} / \mathrm{L}$ in Enriched diet, $p=1.00$ ). Regarding uric nitrogen, a similar concentration was shown for both diets (Figure $5 \mathrm{~b})$ and uric nitrogen increased during the experiment $(+0.7 \mathrm{mmol} / \mathrm{L}$ in both lines; $p=0.99$ ). Total bilirubin was similar in both diets (Figure $5 \mathrm{c}$ ) and decreased during the experiment $(-0.3 \mu \mathrm{mol} / \mathrm{L}$ in Control diet, $p=0.92 ;-0.4 \mu \mathrm{mol} / \mathrm{L}$ in Enriched diet, $p=0.96)$. 


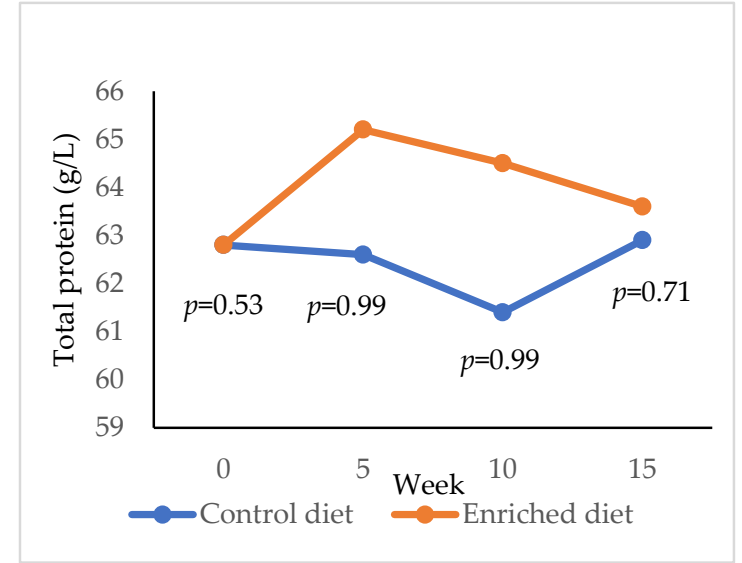

(a)

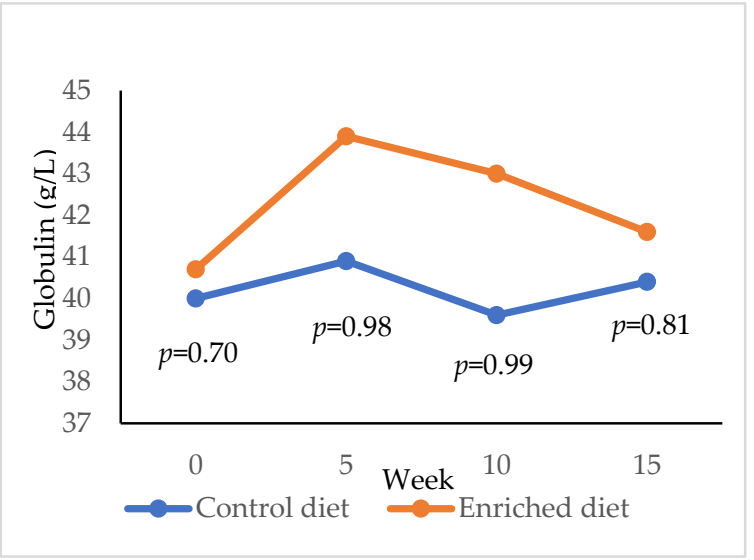

(b)

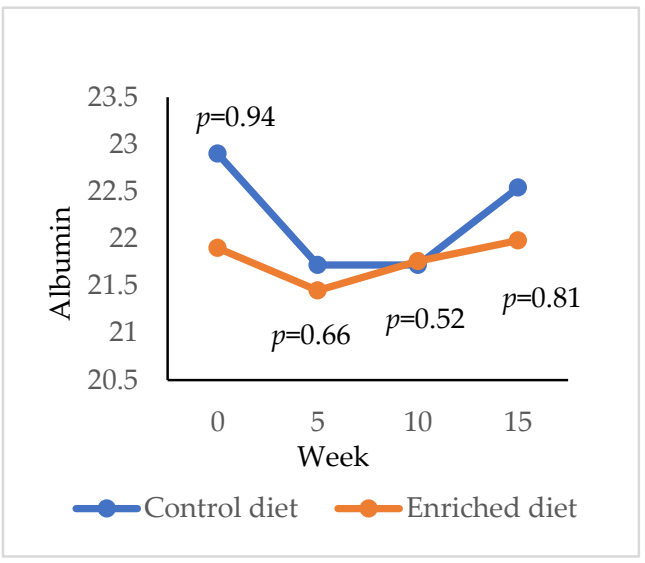

(c)

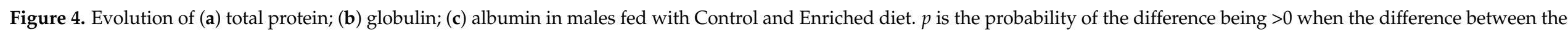
diets was $>0$ or being $<0$ when this difference was $<0$.

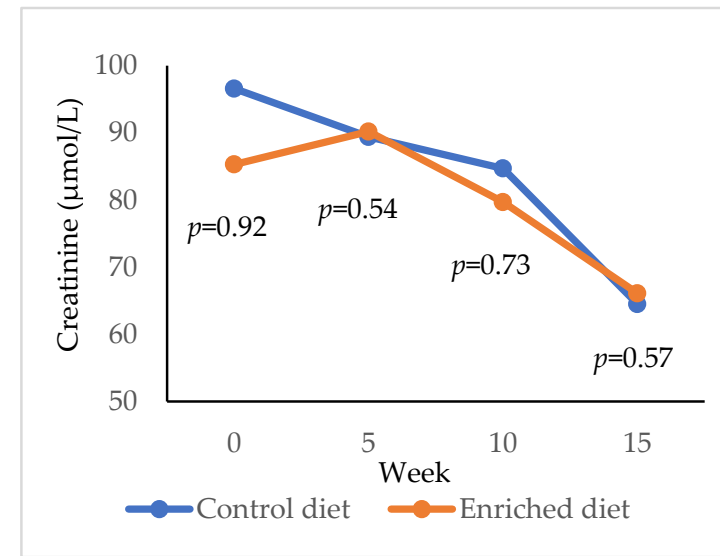

(a)

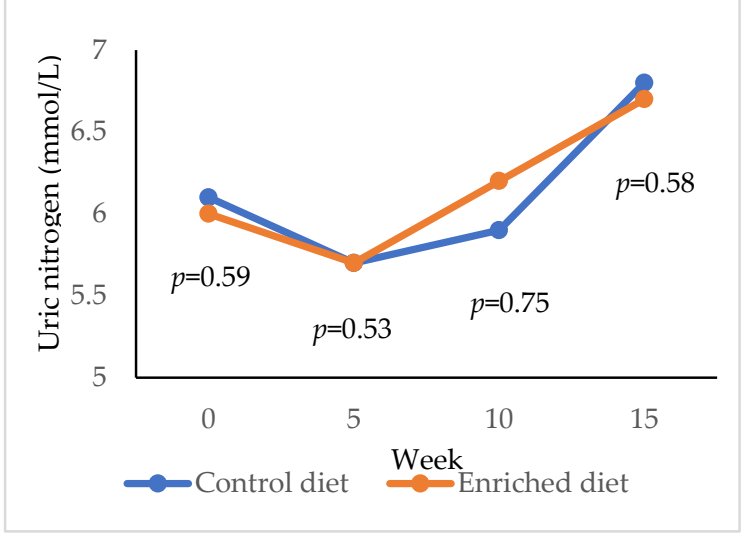

(b)

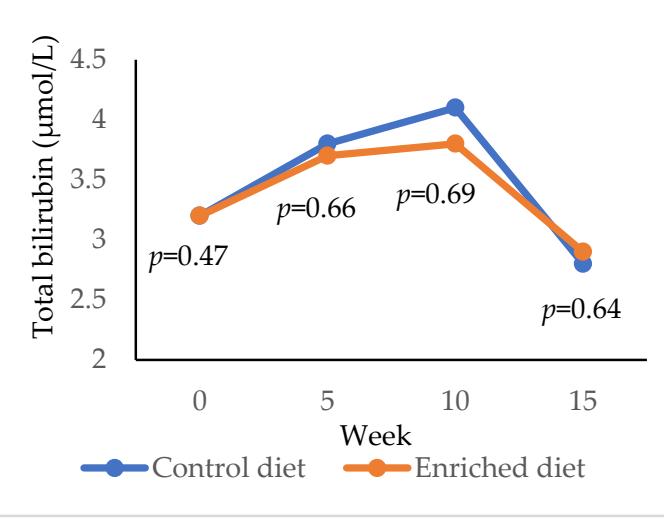

(c)

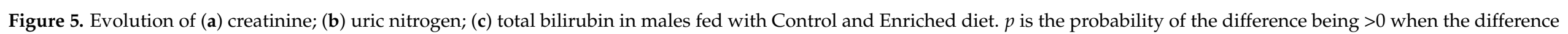
between the diets was $>0$ or being $<0$ when this difference was $<0$. 
The results for calcium, phosphorus, potassium and sodium are presented in Figure 6. Calcium was higher in Control diet both at 0 weeks $(p=0.93)$ and at 15 weeks $(p=0.97)$ and phosphorus was lower at 4 weeks $(p=0.90)$ and 15 weeks $(p=0.92)$. Potassium and sodium were similar for the two diets throughout the experimentation period.

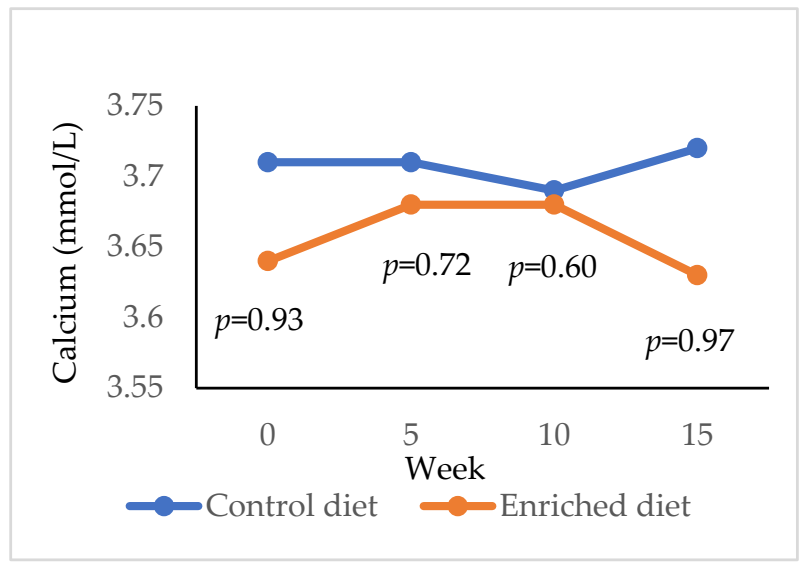

(a)

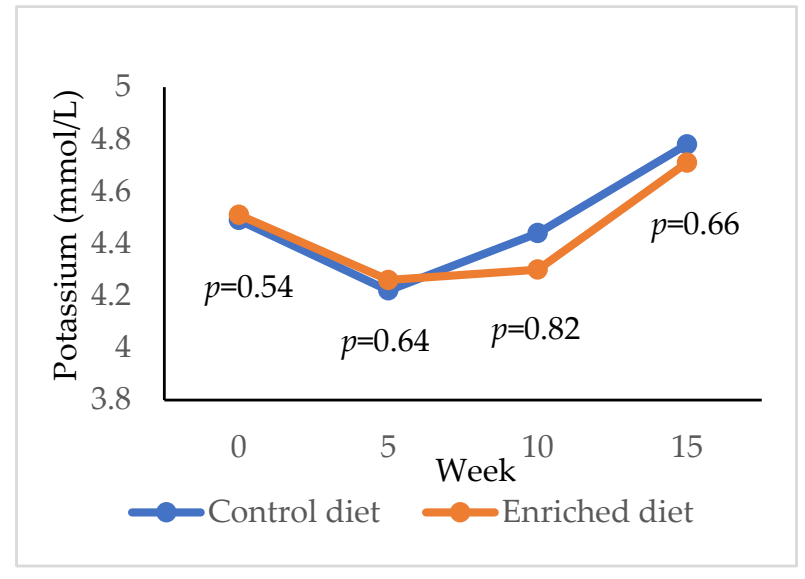

(c)

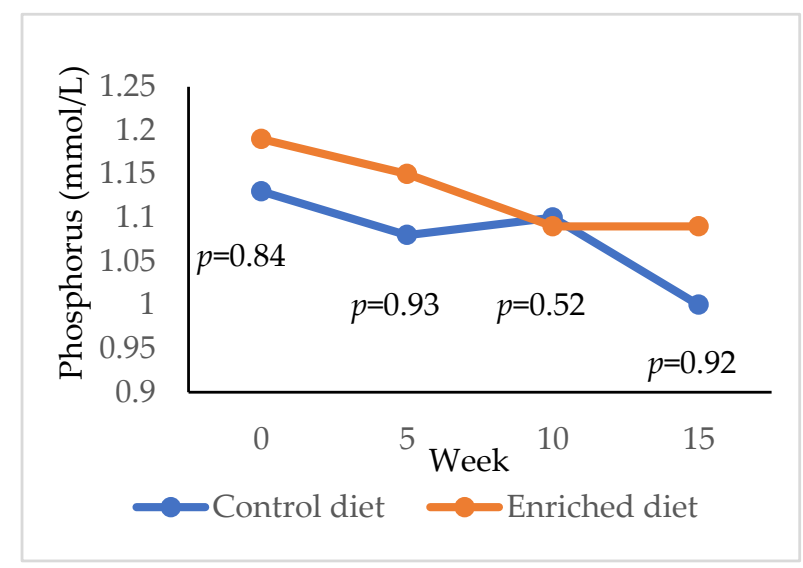

(b)

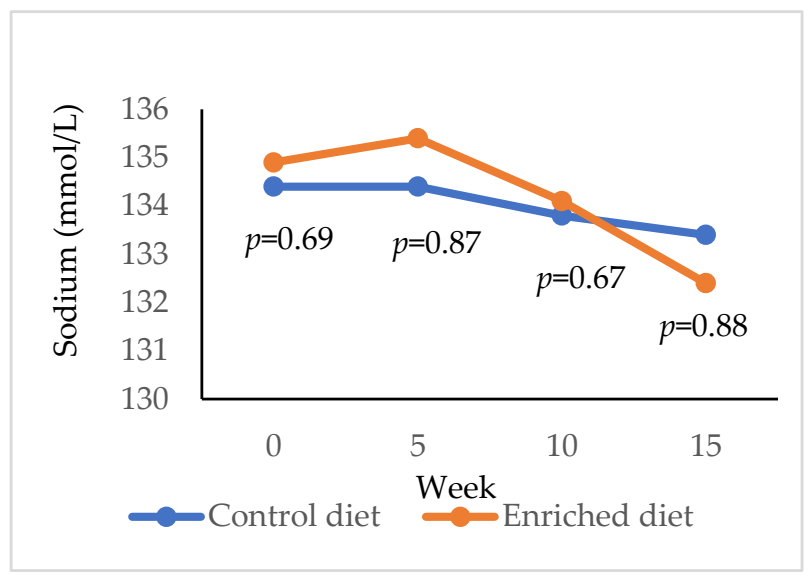

(d)

Figure 6. Evolution of (a) calcium; (b) phosphorous; (c) potassium; (d) sodium in males fed with Control and Enriched diet. $p$ is the probability of the difference being $>0$ when the difference between the diets was $>0$ or being $<0$ when this difference was $<0$.

\section{Discussion}

There is increasing evidence of the role of postbiotics as health promoter. The beneficial effects of postbiotics are mediated through an interaction between the microbial products and the host [10]. In this study, we tested the effectiveness of a postbiotic formulated with a fermented food product in terms of semen quality and health status of male rabbits. Postbiotics have recently demonstrated the ability to improve welfare and health in diabetic rats [16] and dairy heifer calves $[19,20]$.

Food intake was lower with the postbiotic than with control diet from the second week. Nevertheless, survival was not affected. When this diet has been applied to dairy heifer calves, there was also a decrease in consumption from week 5 of intake [19].

Many studies have been carried out to improve the seminal quality in rabbits by supplementing feed with probiotics [21,22]. To the best of our knowledge, no information has been found regarding postbiotics. In our experiment, a slight improvement in the acrosome integrity and spermatozoa with normal tail was obtained in the Enriched diet, although an increase in motility was not achieved. 
Hematological parameters provide valuable information on the health status of the animal. In the present study, the hematological profiles were within the range for healthy rabbits both at the beginning and end of the experiment and for both diets $[18,23]$. Levels of albumin, alkaline phosphatase, alanine aminotransferase, total bilirubin, total protein, globulin, glucose, creatinine, uric nitrogen and amylase are within the wide range of values reported in rabbits $[18,24,25]$.

Alanine aminotransferase and alkaline phosphatase are markers of hepatic diseases $[26,27]$ and alkaline phosphatase is also related to other disorders such as increased bone deposits, intestinal damage, hyperthyroidism and generalized tissue damage [28]. Males fed with postbiotic diet showed lower alanine aminotransferase and alkaline phosphatase concentration, thus the liver profile was improving. The benefit of the postbiotic on liver function has also been demonstrated in rats [16]. Alanine aminotransferase decreased in meat rabbits fed with lactic acid bacteria additives [29]. Moreover, a negative correlation between these biomarkers in plasma and semen quality, mainly the motility and the acrosomal damage, has been reported in rabbits [30] and in goats [31]. As previously mentioned, the improvement in acrosome and tail would agree with this result.

Elevated glucose levels are generally due to various stress factors [32]. Several studies have reported the hypoglycemic effect of probiotic and fermented products [33,34]. Our result indicates that amylase tends to be lower with the postbiotic. This effect is not immediate, but it occurs after consuming the diet for 10 weeks. Although the glucose levels were not modified in this study, they were attenuated with the fermented food product in rats due to changes in the gut microbiota composition [16].

Principal plasma proteins are albumin and globulin [35]. Globulin can be considered as a good indicator of immunity response [36]. The fermented product increased total protein by $2.5 \%$ and globulin by $5.2 \%$, whereas the albumin concentration was similar in both diets. Thus, it could be indicated that postbiotic improves immunity to infectious agents. Similar results have been obtained in calves supplemented with this postbiotic [21]. It has been found that postbiotics from Lactobacillus plantarum also confer anti-inflammatory responses, as observed in a study in porcine intestinal epithelial cell lines [37]. Regarding seminal quality, higher levels of albumin decrease sperm abnormality and increase acrosomal integrity, whereas these parameters are not affected by total protein and globulin [38]. So, the increase in globulins and total proteins does not seem to have a direct effect on the improvement of sperm quality.

We measured uric nitrogen and creatinine as biomarkers of kidney function status. The results indicate that kidney function was not affected by the use of the postbiotic, as both biomarkers evolved in a similar way during the experiment for the Control and Enriched diet. Uric nitrogen could serve as substrate for reactive oxygen species and thus protect important biomolecules against oxidative damage of the spermatozoa [39]. Nevertheless, no significant changes in concentration of uric nitrogen either in semen plasma or blood are provided with supplemented diets [40].

Little information is available on supplementation of blood minerals in response to postbiotics. Minerals act as structural and functional cofactors in metal-containing enzymes [41]. In addition, phosphorus is part of the ATP molecule, which is the major energy source for cellular function [42]. The postbiotic increased phosphorous levels in rabbit blood. This finding is supported in rabbits fed with probiotics and an improvement in the metabolic state of the rabbits could be expected [41]. It is well known that increased concentrations of phosphorous are associated with increased fertility of males [40]. Nevertheless, the results regarding calcium are not conclusive. The postbiotic equalizes the calcium levels of the animals with those of the Control diet, although the calcium decreased to the initial values in the last week of treatment. 


\section{Conclusions}

In conclusion, postbiotics based on lactic acid bacteria improve the health status of rabbit males, especially with respect to the liver function. Sperm quality was also improved, specifically the quality of the tail and acrosome of the spermatozoid. The improvement in postbiotic intake should be investigated, as it could affect results obtained in the long term.

Author Contributions: Conceptualization, M.-L.G. and J.V.D.C.; formal analysis, M.-L.G. and M.-J.A.; writing—original draft preparation, M.-L.G.; writing—review and editing, M.-L.G., M.-J.A., J.V.D.C. All authors have read and agreed to the published version of the manuscript.

Funding: This research was funded by PENTABIOL.

Institutional Review Board Statement: The study was conducted according to the guidelines of the Council Directives 98/58/EC and 2010/63/EU and approved by the University Miguel Hernández of Elche Research Ethics Committee (reference number 2019/VSC/PEA/0163 approved on 5 September 2019).

Informed Consent Statement: Not applicable.

Data Availability Statement: The data presented in this study are available on request from the corresponding author.

Conflicts of Interest: The authors declare no conflict of interest.

\section{References}

1. Hill, C.; Guarner, F.; Reid, G.; Gibson, G.R.; Merenstein, D.J.; Pot, B.; Morelli, L.; Canani, R.B.; Flint, H.J.; Salminen, S.; et al. The international scientific association for probiotics and prebiotics consensus on the scope and appropriate use of the term probiotic. Nat. Rev. Gastroenterol. Hepatol. 2014, 11, 506-514. [CrossRef] [PubMed]

2. Sarowska, J.; Choroszy-Król, I.; Regulska-Ilow, B.; Frej-Mąrzak, M.; Jama-Kmiecik, A. The therapeutic effect of probiotic bacteria on gastrointestinal diseases (Review). Adv. Clin. Exp. Med. 2013, 22, 759-766. [PubMed]

3. Bron, P.A.; Tomita, S.; Mercenier, A.; Kleerebezem, M. Cell surface-associated compounds of probiotic lactobacilli sustain the strain-specificity dogma. Curr. Opin. Microbiol. 2013, 16, 262-269. [CrossRef]

4. Nader-Macías, M.E.F.; Otero, M.C.; Espeche, M.C.; Maldonado, N.C. Advances in the design of probiotic products for the prevention of major diseases in dairy cattle. J. Ind. Microbiol. Biotechnol. 2008, 35, 1387-1395. [CrossRef] [PubMed]

5. Kelsey, A.J.; Colpoys, J.D. Effects of dietary probiotics on beef cattle performance and stress. J. Vet. Behav. 2018, 27, 8-14. [CrossRef]

6. Dowarah, R.; Verma, A.K.; Agarwal, N. The use of Lactobacillus as an alternative of antibiotic growth promoters in pigs: A review. Anim. Nutr. 2017, 3, 1-6. [CrossRef] [PubMed]

7. Zhang, J.L.; Xie, Q.M.; Ji, J.; Yang, W.H.; Wu, Y.B.; Li, C.; Ma, J.Y.; Bi, Y.Z. Different combinations of probiotics improve the production performance, egg quality, and immune response of layer hens. Poult. Sci. J. 2012, 91, 2755-2760. [CrossRef]

8. Bhatt, R.S.; Agrawal, A.R.; Sahoo, A. Effect of probiotic supplementation on growth performance, nutrient utilization and carcass characteristics of growing Chinchilla rabbits. J. Appl. Anim. Res. 2017, 45, 304-309. [CrossRef]

9. Aguilar-Toalá, J.E.; Garcia-Varela, R.; Garcia, H.S.; Mata-Haro, V.; González-Córdova, A.F.; Vallejo-Cordoba, B.; HernádezMendoza, A. Postbiotics: An evolving term within the functional foods field. Trends Food. Sci. Technol. 2018, 75, 105-114. [CrossRef]

10. Teame, T.; Wang, A.; Xie, M.; Zhang, Z.; Yang, Y.; Ding, Q.; Gao, C.; Olsen, R.E.; Ran, C.; Zhou, Z. Paraprobiotics and postbiotics of probiotic Lactobacilli, their positive effects on the host and action mechanisms: A Review. Front. Nutr. 2020, 7, 570344. [CrossRef]

11. Humam, A.M.; Loh, T.C.; Foo, H.L.; Samsudin, A.A.; Mustapha, N.M.; Zulkifli, I.; Izuddin, W.I. Effects of feeding different postbiotics produced by Lactobacillus plantarum on growth performance, carcass yield, intestinal morphology, gut microbiota composition, immune status, and growth gene expression in broilers under heat stress. Animals 2019, 9, 644. [CrossRef] [PubMed]

12. Saettone, V.; Biasato, I.; Radice, E.; Schiavone, A.; Bergero, D.; Meineri, G. State-of-the-art of the nutritional alternatives to the use of antibiotics in humans and monogastric animals. Animals 2020, 10, 2199. [CrossRef]

13. García, M.L.; Argente, M.J. The genetic improvement in meat rabbits. In Lagomorpha Characteristics; Intechopen: London, UK, 2020. [CrossRef]

14. Catellini, C.; Dal Bosco, A.; Arias-Álvarez, M.; Lorenzo, P.L.; Cardinali, R.; Garcia Rebollar, P. The main factors affecting the reproductive performance of rabbit does: A review. Anim. Reprod. Sci. 2010, 122, 174-182. [CrossRef] [PubMed]

15. García-Tomás, M.; Sánchez, J.P.; Rafel, O.; Ramón, J.; Piles, M. Variability, repeatability and phenotypic relationships of several characteristics of production and semen quality in rabbit. Anim. Reprod. Sci. 2006, 93, 88-100. [CrossRef]

16. Cabello-Olmo, M.; Oneca, M.; Torre, P.; Sainz, N.; Moreno-Aliaga, M.J.; Guruceaga, E.; Díaz, J.V.; Encio, I.J.; Barajas, M.; Araña, M. A fermented food product containing lactic acid bacteria protects ZDF rats from the development of type 2 diabetes. Nutrients 2019, 11, 2530. [CrossRef] 
17. Argente, M.J.; García, M.L.; Zby`novká, K.; Petruška, P.; Capcarová, M.; Blasco, A. Correlated response to selection for litter size environmental variability in rabbit's resilience. Animal 2019, 13, 2348-2355. [CrossRef]

18. Beloumi, D.; Blasco, A.; Muelas, R.; Santacreu, M.A.; García, M.L.; Argente, M.J. Inflammatory correlated response in two lines of rabbit selected divergently for litter size environmental variability. Animal 2020, 10, 1540. [CrossRef] [PubMed]

19. Rovai, M.; Guifarro, L.; Anderson, J.; Salama, A.A.K. Effects of long-term postbiotic supplementation on dairy heifer calves: Performance and metabolic indicators. Abstracts of the 2019 American Dairy Science Association. Annual Meeting 23-26 June 2019 Cincinnati, Ohio. J. Dairy Sci. 2019, 102 (Suppl. 1), 218-219.

20. Rovai, M.; Guifarro, L.; Salama, A.A.K. Effects of long-term postbiotic supplementation on dairy heifer calves: Health status and wound healing after dehorning. Abstracts of the 2019 American Dairy Science Association. Annual Meeting 23-26 June 2019 Cincinnati, Ohio. J. Dairy Sci. 2019, 102 (Suppl. 1), 221.

21. Attia, Y.A.; Ibrahim, K. Semen quality, testosterone, seminal plasma biochemical and antioxidant profiles of rabbit bucks fed diets supplemented with different concentrations of soybean lecithin. Animal 2012, 6, 824-833. [CrossRef]

22. Helal, F.I.S.; El- Badawi, A.Y.; Abou-Ward, G.A.; El-Naggar, S.; Hassan, A.A.; Basyoney, M.M.; Morad, A.A.A. Semen quality parameters of adult male NZW rabbits fed diets added with two different types of probiotics. Egypt. J. Nutr. Feed. 2018, 21, 125-132. [CrossRef]

23. Massányi, M.; Kohút, L.; Argente, M.J.; Halo, M.; Kováčik, A.; Kováčiková, E.; Ondruška, L.; Formicki, G.; Massányi, P. The effect of different sample collection methods on rabbit blood parameters. Saudi J. Biol. Sci. 2020, 27, 3157-3160. [CrossRef]

24. Leineweber, C.; Müller, E.; Marschang, R.E. Blood reference intervals for rabbits (Oryctolagus cuniculus) from routine diagnostic samples. Best immung von Blutreferenzwerten für Kaninchen (Oryctolagus cuniculus) aus Routine diagnostic proben. Tierarztl Prax Ausg K Kleintiere Heimtiere 2018, 46, 393-398. [CrossRef] [PubMed]

25. Washington, I.M.; Van Hoosier, G. Clinical Biochemistry and Hematology. In The Laboratory Rabbit, Guinea Pig, Hamster, and Other Rodents; Suckow, M.A., Stevens, K.A., Wilson, R.P., Eds.; Elsevier: Amsterdam, The Netherlands, 2012; pp. 57-116.

26. Dontas, I.A.; Marinou, K.A.; Iliopoulos, D.; Tsantila, N.; Agrogiannis, G.; Papalois, A.; Karatzas, T. Changes of blood biochemistry in the rabbit animal model in atherosclerosis research; a time or stress-effect. Lipids Health Dis. 2011, 10, 139. Available online: http: / / www.lipidworld.com/content/10/1/139 (accessed on 15 March 2021). [CrossRef] [PubMed]

27. Kim, W.; Flamm, S.L.; Di Bisceglie, A.M.; Bodenheimer, H.C. Serum activity of alanine amino transferase (ALT) as an indicator of health and disease. Hepatology 2008, 47, 1363-1370. [CrossRef]

28. Fraser, C.M. Merck Veterinary Manual, 6th ed.; Ocean: Barcelona, Spain, 2007; p. 1314.

29. Shah, A.A.; Liu, Z.; Chen, Q.; Juanzi, W.; Sultana, N.; Zhong, X. Potential effect of the microbial fermented feed utilization on physicochemical traits, antioxidant enzyme and trace mineral analysis in rabbit meat. J. Anim. Physiol. Anim. Nutr. 2019, 104, 767-775. [CrossRef]

30. Yousef, M.I.; Abdallah, G.A.; Kamel, K.I. Effect of ascorbic acid and Vitamin E supplementation on semen quality and biochemical parameters of male rabbits. Anim. Reprod. Sci. 2003, 76, 99-111. [CrossRef]

31. Chauhan, M.S.; Kapila, R.; Gandhi, K.K.; Anand, S.R. Acrosome damage and enzyme leakage of goat spermatozoa during dilution, cooling and freezing. Andrologia 1993, 26, 21-26. [CrossRef]

32. Jenkins, J.R. Rabbit diagnostic testing. J. Exot. Pet. Med. 2008, 17, 4-15. [CrossRef]

33. Sivamaruthi, B.S.; Kesika, P.; Prasanth, M.I.; Chaiyasut, C. A Mini Review on Antidiabetic Properties of 833 Fermented. Nutrients 2018, 10, 1973. [CrossRef]

34. Ebringer, L.; Ferenčík, M.; Krajčovič, J. Beneficial Health Effects of Milk and Fermented Dairy. Folia Microbiol. 2008, 53, 378-394. [CrossRef]

35. Andonova, M. Role of innate defense mechanisms in acute phase response against Gram-Negative agents. Bulg. J. Vet. Med. 2002, 5, 77-92.

36. Abdel-Azeem, A.S.; Abdel-Azim, A.M.; Darwish, A.A.; Omar, E.M. Hematological and biochemical observations in four pure breeds of rabbits and their crosses under Egyptian environmental conditions. World Rabbit Sci. 2010, 18, 103-110. [CrossRef]

37. Kim, K.W.; Kang, S.S.; Woo, S.J.; Park, O.J.; Ahn, K.B.; Song, K.D.; Lee, H.J.; Yun, C.H.; Han, S.H. Lipoteichoic acid of probiotic Lactobacillus plantarum attenuates Poly I:C-induced IL-8 production in porcine intestinal epithelial cells. Front. Microbiol. 2017, 8, 1827. [CrossRef] [PubMed]

38. Sun, Y.; Dong, G.; Liao, M.; Tao, L.; LV, J. The effects of low levels of aflatoxin B1 on health, growth performance and reproductivity in male rabbits. World Rabbit Sci. 2018, 26, 123-133. [CrossRef]

39. Xu, C.; Yu, C.; Xu, L.; Miao, M.; Li, Y. High serum uric acid increases the risk for nonalcoholic fatty liver disease: A prospective observational study. PLoS ONE 2010, 5, 11578. [CrossRef] [PubMed]

40. Vizzari, F.; Massány, M.; Knížatová, N.; Corino, C.; Rossi, R.; Ondrŭska, L.; Tirpák, F.; Halo, M.; Massány, P. Effects of dietary plant polyphenols and seaweed extract mixture on male-rabbit semen: Quality traits and antioxidant markers. Saudi J. Biol. Sci. 2021, 28, 1017-1025. [CrossRef]

41. Shah, A.A.; Yuan, X.; Khan, R.U.; Shao, T. Effect of lactic acid bacteria-treated King grass silage on the performance traits and serum metabolites in New Zealand white rabbits (Oryctlagus cuniculus). J. Anim. Physiol. Anim. Nutr. 2018, 102, 902-908. [CrossRef] [PubMed]

42. Jabs, C.M.; Ferrell, W.J.; Robb, H.J. Plasma Changes in Endotoxin and Anaphylactic Shock (ATP, ADP and Creatine Phosphorus). Ann. Clin. Lab. Sci. 1979, 9, 121-132. 